\title{
Resveratrol enhances the sensitivity of cholangiocarcinoma to chemotherapeutic agents
}

\author{
Gabriel A Frampton ${ }^{1,2}$, Eric A Lazcano ${ }^{3}$, Huang $\mathrm{Li}^{1,2,4}$, Akimuddin Mohamad ${ }^{1,2}$ and Sharon DeMorrow ${ }^{1,2}$
}

Cholangiocarcinomas are devastating cancers that are resistant to chemotherapies. Resveratrol, a food-derived polyphenol with antitumorigenic properties, can regulate the expression of cytochrome p450 1b1 (Cyp1b1), which may confer chemoresistance in various cancers. Our aims were to assess the effects of resveratrol on the sensitivity of cholangiocarcinoma cells to chemotherapeutic agents and show an association between Cyp1b1 expression and chemosensitivity. Cholangiocarcinoma cell lines were treated with resveratrol before the addition of 5-fluorouracil (5-FU), gemcitabine, or mitomycin C. Cell proliferation and apoptosis were assessed by MTS assays and Annexin staining. Resveratrol effects on cholangiocarcinoma tumor sensitivity to 5-FU was assessed in an in vivo xenograft model using Mz-ChA-1 cells. After resveratrol treatment, Cyp1b1 expression was assessed by real-time PCR and immunoblotting. Stable-transfected cell lines with Cyp1b1 expression knocked down (Mz-Cyp1b1) were used to assess sensitivity to chemotherapeutic agents by MTS assays and Annexin staining and in a xenograft model using Mz-ChA-1 and Mz-Cyp1b1 cells, respectively. For each chemotherapeutic agent, co-treatment with resveratrol in vitro decreased cell proliferation and increased apoptosis to a greater extent than with the chemotherapeutic agent alone. In vivo, 5-FU + resveratrol decreased tumor size and increased TUNEL staining to a greater extent than 5-FU alone. In parallel, resveratrol decreased Cyp1b1 expression in Mz-ChA-1 cells and in cholangiocarcinoma tumors. Mz-Cyp1b1 cells were more sensitive to chemotherapeutic agents in vitro than mock-transfected cells, and Mz-Cyp1b1-induced tumors were more susceptible to 5 -FU treatment. We suggest that resveratrol treatment may be a useful adjunct therapy to improve chemosensitivity in cholangiocarcinoma.

Laboratory Investigation (2010) 90, 1325-1338; doi:10.1038/labinvest.2010.99; published online 10 May 2010

KEYWORDS: adjunct therapy; biliary cancer; cytochrome p450 1b1; polyphenols

Cholangiocarcinoma originates from the neoplastic transformation of epithelial cells that line the intra- and extrahepatic bile ducts. ${ }^{1-4}$ Symptoms are usually only evident after blockage of the bile duct, and at this late stage, chemotherapy and radiotherapy are relatively ineffectual leaving surgical resection as the only option for treatment. ${ }^{1-4}$ Owing to this, these biliary cancers have a poor prognosis and improved treatments for this tumor are urgently needed.

Alternative adjunct therapies for these chemoresistant cancers are currently being explored. A large body of research has focused on plant-derived polyphenols, such as resveratrol, ${ }^{5-7}$ caffeic acid, ${ }^{8}$ tannic acid, ${ }^{9}$ and green-tea polyphenols ${ }^{10}$ as therapeutic and chemopreventive agents.
Research indicates that these polyphenols may have antioxidant characteristics with potential health benefits including reducing the risk of cancer. ${ }^{11}$ We have shown that caffeic acid, a polyphenol extracted from the propolis of honeybee hives, exerts antiproliferative effects on cholangiocarcinoma ${ }^{8}$ and other tumor types ${ }^{12-14}$ in vitro and in vivo by inhibiting the nuclear factor- $\kappa$-B pathway. ${ }^{8}$ Furthermore, high concentrations of resveratrol have been shown to be antiproliferative in a cholangiocarcinoma cell line ${ }^{5}$ as well as in other tumor types ${ }^{15-19}$ through a number of different mechanisms including increased cyclooxygenase 2 expression, ${ }^{15}$ activation of Forkhead proteins, ${ }^{16}$ facilitation of death receptor complex formation, ${ }^{17,18}$ or cell cycle arrest. ${ }^{19}$

\footnotetext{
${ }^{1}$ Department of Internal Medicine, Texas A\&M Health Science Center College of Medicine, Temple, TX, USA; ${ }^{2}$ Digestive Disease Research Center, Department of Internal Medicine, Scott \& White Hospital, Temple, TX, USA; ${ }^{3}$ Department of Research and Education, Scott \& White Hospital, Temple, TX, USA and ${ }^{4}$ Department of Hepatobiliary Surgery, First Affiliated Hospital, Sun Yat-sen University, Guangzhou, China

Correspondence: Dr S DeMorrow, PhD, Department of Internal Medicine, Scott and White Hospital and Texas A\&M Health Science Center, Medical Research Building 702 SW H.K. Dodgen Loop, Temple, TX 76504, USA.

E-mail: demorrow@medicine.tamhsc.edu

Received 9 February 2010; accepted 8 April 2010
} 
Although it is interesting that these food-derived polyphenols exert antiproliferative effects on tumor growth in their own right, often the concentrations required are prohibitive for these compounds to be considered as viable treatment options. A more rational approach is to study the efficacy of these compounds as adjunct therapies to existing chemotherapeutic strategies. For example, tannic acid and the green-tea polyphenol, epigallocatechin gallate have been shown to sensitize cholangiocarcinoma to chemotherapyinduced apoptosis in vitro. ${ }^{9,10}$ Furthermore, the green-tea polyphenol administered together with gemcitabine not only slowed cholangiocarcinoma tumor progression in a xenograft mouse model, but it also resulted in a decrease in the tumor volume. ${ }^{10}$ However, similar effects of resveratrol on the chemotherapy sensitivity of cholangiocarcinoma have not been addressed.

Resveratrol is a polyphenol found naturally in red wine, grapes, and peanuts. The compound has been reported to be a preventative agent against carcinogenesis, having the ability to suppress cancer initiation and promotion, as well as disrupt phases of tumor initiation, promotion, and progression. ${ }^{20}$ It has additionally been shown to prevent chemical carcinogen-induced epithelial cell transformation. ${ }^{21,22}$ In cholangiocarcinoma cell lines, resveratrol has been shown to perturb cell cycle progression, resulting in an accumulation of cells in the $G_{1} / S$ phase $;{ }^{5}$ however, the precise mechanism by which this occurs is largely unknown.

Resveratrol treatment has earlier been shown to downregulate the expression and activity of cytochrome p450 $1 \mathrm{~b} 1$ (Cyp1b1) in various cell lines. ${ }^{23-25}$ Cyp1b1 has many functions, including the hydroxylation of 17 -estradiol, ${ }^{26}$ the biotransformation of testosterone ${ }^{27}$ as well as the metabolism of xenobiotics such as ethoxyresorufin, theophylline, and caffeine. ${ }^{28}$ It has been shown to be upregulated in a large number of cancers such as ovarian cancer, ${ }^{29}$ endometrial cancer, ${ }^{30}$ and non-small cell lung cancer. ${ }^{31}$ The significance of Cyp 1 b1 overexpression in cancer is not fully understood, but the fact that it can inactivate flutamide, an antiandrogen used in the treatment of prostate cancer, with high efficiency suggests that this enzyme might have an important function in the development of resistance to some forms of chemotherapy. ${ }^{32}$ In addition, increased Cyp1b1 expression has been shown to confer resistance to docetaxel, ${ }^{33}$ although no metabolites of this drug could be observed after exposure to recombinant Cyp1b1, ${ }^{34}$ suggesting that the precise mechanism for the enhanced chemoresistance associated with Cyp1b1 overexpression is largely unknown.

In this study, we show that low concentrations of resveratrol that have little or no toxicity in cholangiocarcinoma cells renders these cells more sensitive to a number of chemotherapeutic agents both in vitro and in vivo. Furthermore, we show that this sensitization is associated with a decrease in the expression of Cyp1b1 and that in parallel, the specific knockdown of Cyp1b1 in these cells also renders them more susceptible to chemotherapy-induced cell death.

\section{MATERIALS AND METHODS \\ Cell Lines}

We used four human cholangiocarcinoma cell lines (Mz-ChA-1, HuCC-T1, CCLP1, and SG231) with different origins. Mz-ChA-1 cells, from human gallbladder, ${ }^{35}$ were a gift from $\mathrm{Dr}$ G. Fitz (University of Texas Southwestern Medical Center, Dallas, TX, USA). CCLP- $1,{ }^{36}$ HuCC-T1, ${ }^{37}$ and SG231, ${ }^{38}$ all from intrahepatic bile ducts, were a kind gift from $\mathrm{Dr} A \mathrm{~J}$ Demetris (University of Pittsburg, PA, USA) and were cultured as described. ${ }^{36-38}$ The human immortalized, non-malignant cholangiocyte cell line, H69 (from Dr GJ Gores, Mayo Clinic, Rochester, MN, USA), was cultured as described. ${ }^{39}$ In addition, the primary human intrahepatic cholangiocyte cell line was purchased from Sciencell (Carlsbad, CA, USA) and cultured according to the manufacturer's instructions.

\section{MTS Cell Proliferation Assays}

MTS assays were performed as described earlier ${ }^{40}$ and were stimulated with various concentrations of resveratrol (5-50 $\mu \mathrm{M}$; Sigma, St Louis, MO, USA) immediately before the addition of either 5-fluoruracil $(1-100 \mu \mathrm{M}$; 5-fluorouracil (5-FU); EMD Biosciences, Gibbstown, NJ, USA), gemcitabine (1-100 $\mu \mathrm{M}$; R\&S Pharmchem, Hangzhou City, China), or mitomycin C (1-50 $\mu \mathrm{M}$; EMD Biosciences). In all cases, data were expressed as the fold change of treated cells as compared with vehicle-treated controls. To determine the approximate $\mathrm{IC}_{50}$ doses, dose response data for each chemotherapeutic agent $(+$ I$20 \mu \mathrm{M}$ resveratrol) was plotted on a linear graph and the average dose required to reach $50 \%$ cell viability was extrapolated.

\section{Annexin V Staining}

Apoptosis was detected by Annexin $\mathrm{V}$ staining after the protocol described earlier. ${ }^{40}$ Briefly, cells were treated with resveratrol $(20 \mu \mathrm{M})$, with or without either 5-FU $(30 \mu \mathrm{M})$, mitomycin $\mathrm{C}(5 \mu \mathrm{M})$, or gemcitabine $(30 \mu \mathrm{M})$ for $24 \mathrm{~h}$. Annexin $\mathrm{V}$ binding was visualized as described earlier ${ }^{40}$ and the percentage of Annexin V-positive cells were counted in five non-overlapping fields per coverslip. Data was expressed as average \pm s.e.m. and significance was assessed using a $t$-test.

\section{Real-Time PCR}

RNA was extracted from cells after treatment with various concentrations of resveratrol $(5-50 \mu \mathrm{M})$ for $24 \mathrm{~h}$, using the RNeasy Mini kit (Qiagen, Valencia, CA, USA) according to the instructions provided by the vendor and reverse transcribed using the Reaction Ready ${ }^{\mathrm{TM}}$ First Strand cDNA synthesis kit (SA Bioscience, Frederick, MD, USA). These reactions were used as templates for the PCR assays using a SYBR Green PCR master mix (SA Bioscience) in the realtime thermal cycler (MX-3005P, Agilent Technologies, Santa Clara, CA, USA) using commercially available primers designed against human Cyp1b1 and GAPDH (SA Bioscience). A $\Delta \Delta C T$ analysis was performed using the untreated cells as the control sample. ${ }^{41,42}$ Data are expressed as relative mRNA levels \pm s.e.m. $(n=3)$. 


\section{Immunoblotting}

Immunoblots to detect Cyplb1 and $\beta$-actin were performed as described earlier ${ }^{40}$ using specific antibodies against each protein (Santa Cruz Biotechnology, Santa Cruz, CA, USA). Data are expressed as fold change (mean \pm s.e.m.) of the relative expression after normalization with $\beta$-actin.
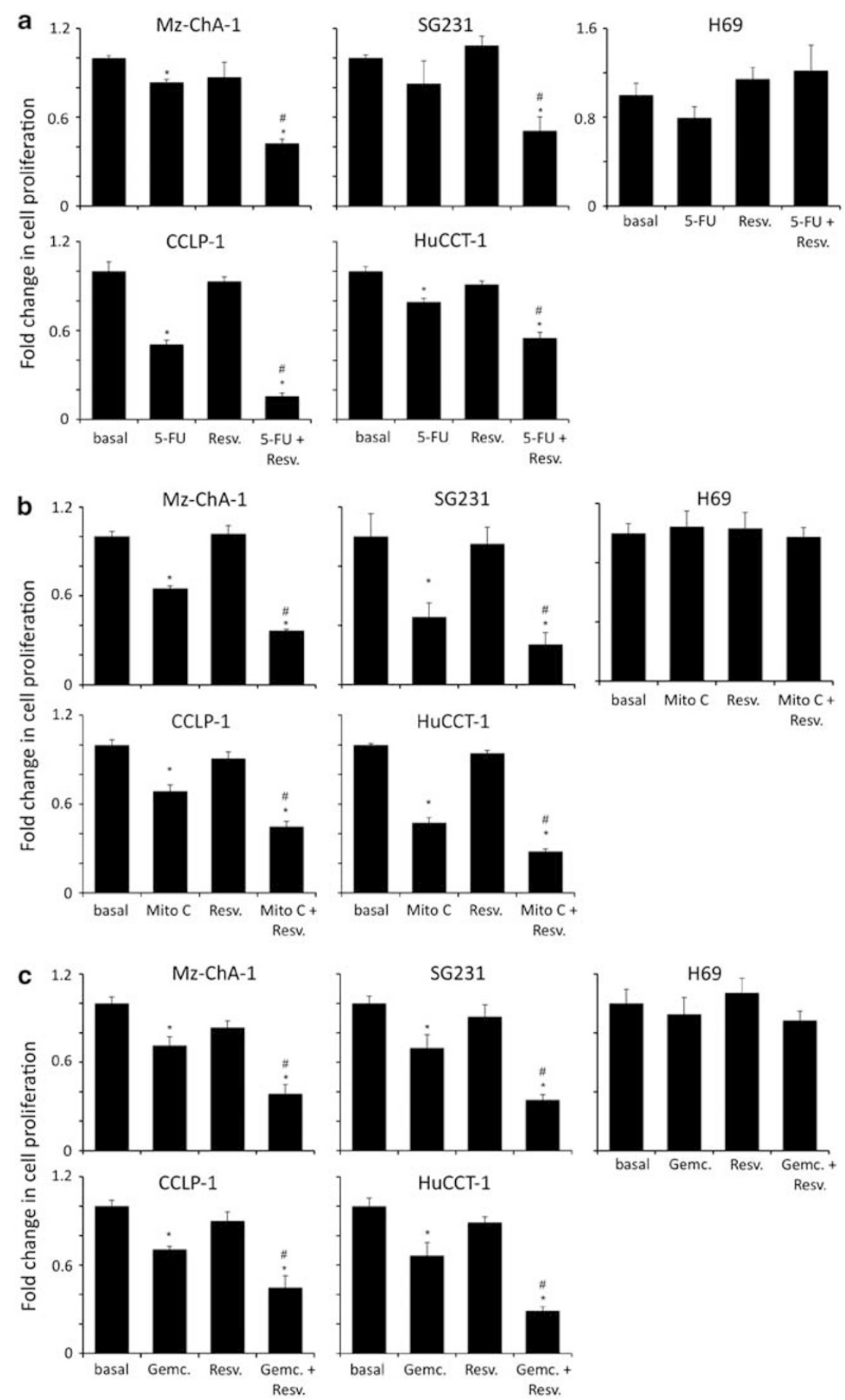

Figure 1 Resveratrol renders cholangiocarcinoma cells, but not non-malignant cholangiocytes, more susceptible to chemotherapeutic agents in vitro. Cholangiocarcinoma cells (Mz-ChA-1, SG231, CCLP-1, and HuCCT-1) and non-malignant human cholangiocytes (H69) were treated with resveratrol (Resv; $20 \mu \mathrm{M}$ ) before the addition of 5-FU ( $30 \mu \mathrm{M} ; \mathbf{a})$, mitomycin C (Mito $\mathrm{C} ; 5 \mu \mathrm{M} ; \mathbf{b})$, or gemcitabine (Gemc; $30 \mu \mathrm{M} ; \mathbf{c})$ for 48 h. Cell proliferation was assessed using an MTS cell proliferation assay. Data are expressed as fold change in proliferation (average \pm s.e.m., $n=7)$. The ${ }^{*}$ denotes significance $(P<0.05)$ compared with basal, and the denotes significance $(P<0.05)$ compared with the chemotherapy treatment alone. 


\section{Establishment of Stable-Transfected Cell Lines}

The function of Cyp1b1 expression in the relative chemoresistance of cholangiocarcinoma cells was shown using cells that have the expression of this gene stably knocked down. These cell lines were established using SureSilencing shRNA (SABiosciences, Frederick, MD) plasmids for human Cyplb1, containing a marker for neomycin resistance for the selection of stably transfected cells after the methodology described earlier. ${ }^{42}$ A number of subsequent clones were then assessed for the relative knockdown of Cyp1b1 using real-time PCR and a single clone with the greatest degree of knockdown was selected for subsequent experiments and were subsequently designated Mz-cyplb1 shRNA and Mz-neo neg (mock-transfected control).

\section{Nude Mice Treatment}

In vivo experiments were performed as described earlier ${ }^{43}$ in accordance with the guidelines of the Scott \& White IACUC committee. Mz-ChA-1 cells $\left(5 \times 10^{6}\right)$ were suspended in $0.25 \mathrm{ml}$ of extracellular matrix gel and injected subcutaneously in the flanks of these animals. After the establishment of the tumors, mice received resveratrol $(20 \mathrm{mg} / \mathrm{kg}$ i.p.) with or without $5-\mathrm{FU}(10 \mathrm{mg} / \mathrm{kg}$ i.p.) injected three times per week. In parallel, mice were injected with Mz-neo neg cells $\left(5 \times 10^{6}\right.$ cells $)$ or Mz-cyp1b1 shRNA cells and treated with $5-\mathrm{FU}(10 \mathrm{mg} / \mathrm{kg}$ i.p. $)$ three times per week. After 38 days, mice were anesthetized with sodium pentobarbital $(50 \mathrm{mg} / \mathrm{kg}$ i.p.) and killed according to

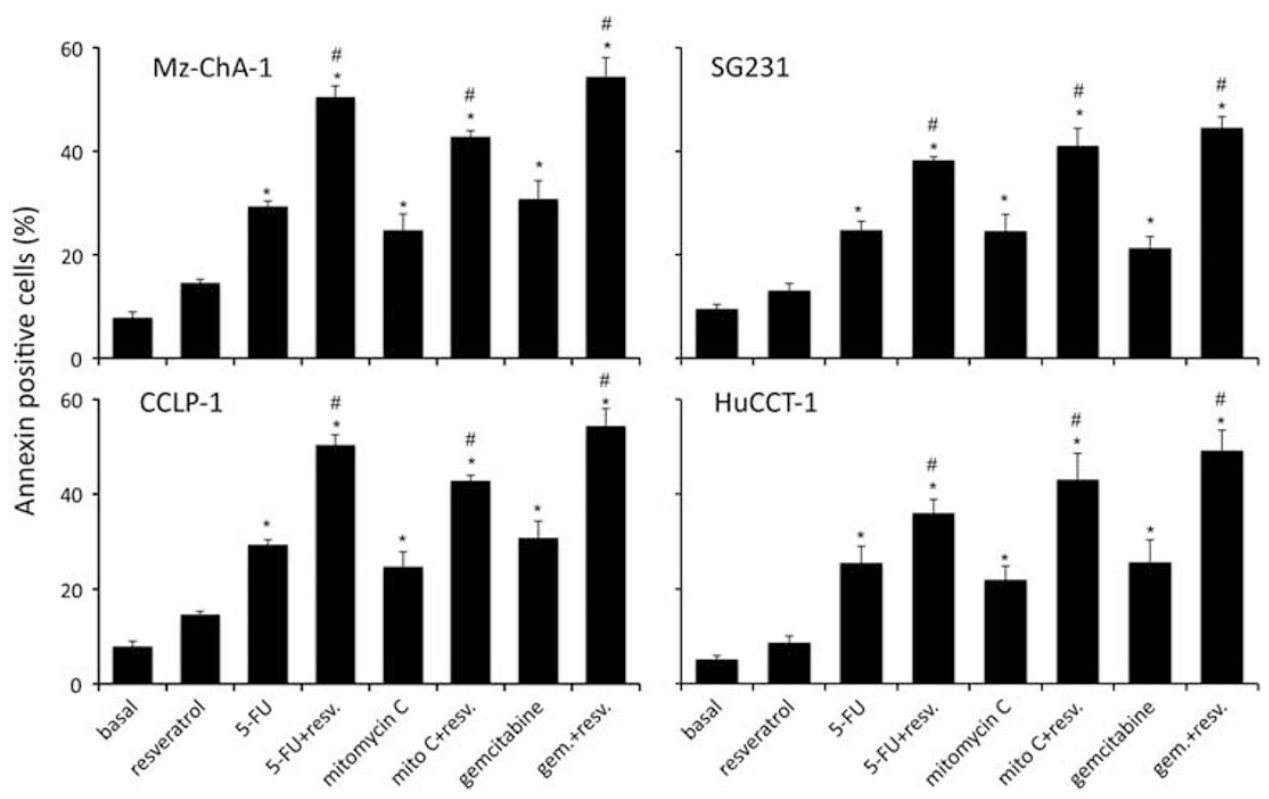

Figure 2 Co-treatment of cholangiocarcinoma cells with resveratrol and chemotherapeutic agents increases the incidence of cell death in vitro. Cholangiocarcinoma cells (Mz-ChA-1, SG231, CCLP-1, and HuCCT-1) were treated with resveratrol (Resv; $20 \mu \mathrm{M}$ ) before the addition of 5-FU (30 $\mu \mathrm{M}$ ), mitomycin C (Mito $\mathrm{C} ; 5 \mu \mathrm{M}$ ), or gemcitabine $(\mathrm{Gemc} ; 30 \mu \mathrm{M})$ for $24 \mathrm{~h}$. Apoptosis was assessed by Annexin $\mathrm{V}$ staining. Data are expressed as a percentage of Annexin V-positive cells per field (average \pm s.e.m., of 10 non-overlapping fields). The ${ }^{\star}$ denotes significance $(P<0.05)$ compared with basal, and the denotes significance $(P<0.05)$ compared with the chemotherapy treatment alone.

Table 1 Efficacy of chemotherapeutic agents

\begin{tabular}{|c|c|c|c|c|c|c|c|c|c|c|}
\hline Chemotherapy & - Resv. & + Resv. & - Resv. & + Resv. & - Resv. & + Resv. & - Resv. & + Resv. & - Resv. & + Resv. \\
\hline 5-FU $(\mu \mathrm{M})$ & 95.01 & 58.99 & 61.12 & 50.72 & 63.09 & 43.49 & 87.48 & 53.07 & 206.3 & 286.3 \\
\hline Mitomycin $(\mu \mathrm{M})$ & 9.56 & 4.39 & 5.40 & 1.27 & 6.12 & 5.15 & 7.39 & 5.95 & 38.93 & 21.52 \\
\hline
\end{tabular}

Cell lines were treated with resveratrol $(20 \mu \mathrm{M})$ before the addition of various concentrations of 5 -FU $(1-100 \mu \mathrm{M})$, mitomycin $\mathrm{C}(1-10 \mu \mathrm{M})$, or gemcitabine $(1-100 \mu \mathrm{M})$. The $\mathrm{IC}_{50}$ dose was calculated as the dose of the chemotherapeutic agent required to inhibit the proliferation to $50 \%$ of the untreated cells in an MTS cell proliferation assay. 
institutional guidelines. Serum was collected and AST and ALT levels were measured using a Dimension $\AA$ RxL Max Integrated Chemistry system (Dade Behring, Deerfield, IL, USA) by the Scott \& White Hospital, Chemistry Department.

Tumor tissues were excised from the flank of these mice, fixed in formalin, and embedded in paraffin. The cholangiocyte marker cytokeratin-19 (CK-19) was evaluated by immunohistochemical staining. ${ }^{44}$ Proliferating cell nuclear antigen (PCNA) immunoreactivity in tumor sections was also evaluated and in parallel, PCNA mRNA expression was evaluated in tumor tissue by real-time PCR. ${ }^{44}$ Apoptosis was detected in these sections using the ApopTag ${ }^{\mathbb{R}}$ peroxidase in situ apoptosis detection kit following the manufacturer's instructions (Millipore; Temucula, CA, USA).

In each case, sections were counterstained with hematoxylin before analysis. Immunohistochemistry observation was taken by BX-40 light microscopy (Olympus, Tokyo, Japan) with a videocam (Model No U-PMTVC; Olympus) and processed with an Image Capturing Software (DP2-BSW; Olympus). Three pathologists independently performed analysis in a blind manner.

\section{RESULTS}

\section{Resveratrol Renders Cholangiocarcinoma Cells More Susceptible to Chemotherapeutic Agents In Vitro}

Resveratrol has earlier been shown to exert antiproliferative effects on cholangiocarcinoma cells in vitro ${ }^{5}$ at high concentrations ( $32 \mu \mathrm{M}$ and above). Initially, we used a fixed concentration of the chemotherapeutic agents studied in four cholangiocarcinoma cell lines and showed that resveratrol concentrations up to $20 \mu \mathrm{M}$ have a synergistic effect on the antiproliferative actions of 5-FU (results from $20 \mu \mathrm{M}$ resveratrol are shown in Figure 1a), mitomycin C (results from $20 \mu \mathrm{M}$ resveratrol are shown in Figure 1b), and gemcitabine (results from $20 \mu \mathrm{M}$ resveratrol are shown in Figure 1c). Doses of resveratrol at $20 \mu \mathrm{M}$ or below had very little cytotoxic effects (Figure 1a, b, and c and data not shown) in these cell lines. Furthermore, analysis of apoptosis using Annexin $\mathrm{V}$ staining showed that resveratrol treatment $(20 \mu \mathrm{M})$ increased the susceptibility of the four cholangiocarcinoma cell lines studied to 5-FU-, mitomycin C-, and gemcitabine-induced apoptosis (Figure 2).

To determine the extent by which resveratrol increases the susceptibility of cholangiocarcinoma cells to the chemotherapeutic agents, we treated cholangiocarcinoma cell lines with $20 \mu \mathrm{M}$ resveratrol followed by various concentrations of 5-FU $(1-100 \mu \mathrm{M})$, mitomycin $\mathrm{C}(1-0 \mu \mathrm{M})$, or gemcitabine $(1-100 \mu \mathrm{M})$. The relative $\mathrm{IC}_{50}$ doses were calculated as described above for each cell line, and after every chemotherapeutic agent, co-treatment with resveratrol decreased the dose required to reduce cholangiocarcinoma cell number by $50 \%$ (Table 1 ).
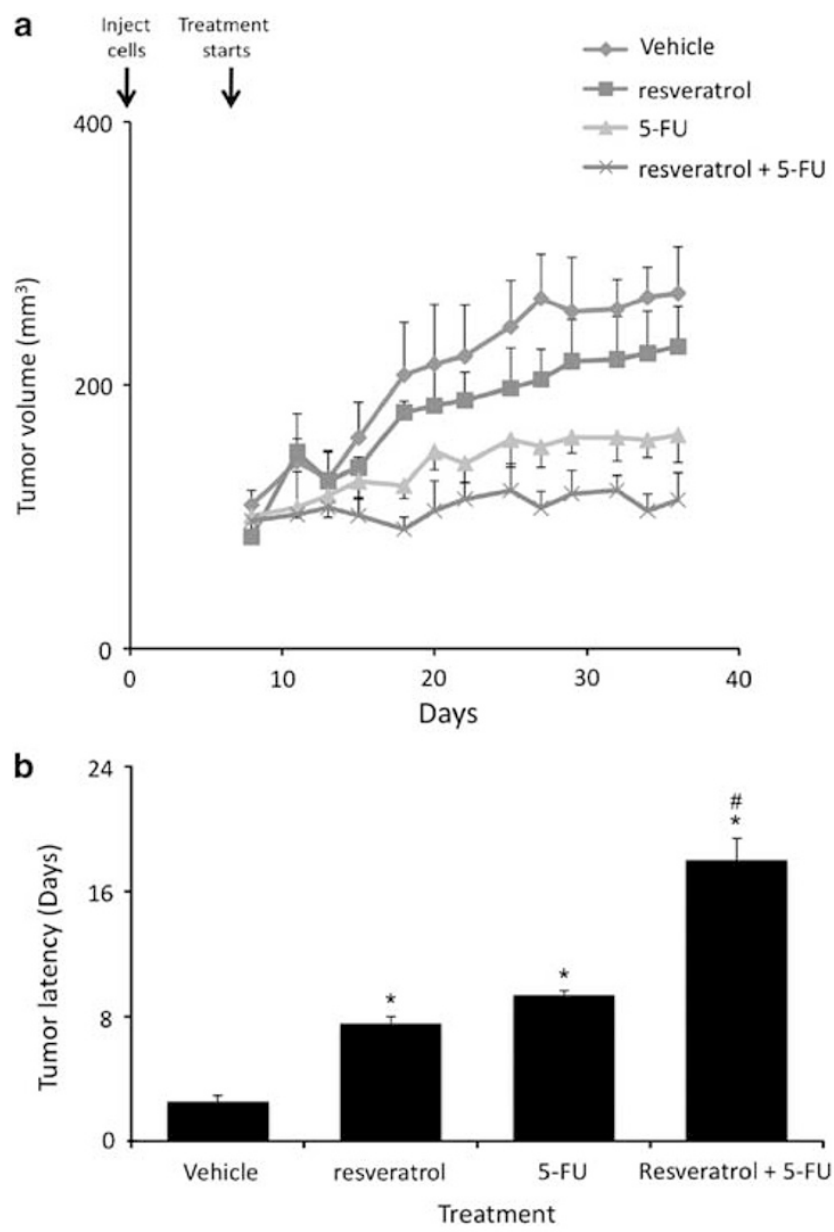

Figure 3 Resveratrol renders xenografted cholangiocarcinoma tumors more susceptible to 5 -FU in vivo. $\mathrm{Mz}$-ChA-1 cells were injected into the flank of athymic mice. After tumors were established, mice were treated with $20 \mathrm{mg} / \mathrm{kg} /$ day (i.p.) of resveratrol, $10 \mathrm{mg} / \mathrm{kg} /$ day of $5-\mathrm{FU}$ or resveratrol and 5 -FU in combination, 3 days per week for 38 days and tumor volume assessed (a). Tumor latency was assessed as the time taken for the tumor to grow to $150 \%$ of the original size (b). Data are expressed as average latency (days \pm s.e.m.) and the ${ }^{*}$ denotes significance $(P<0.05)$ from vehicle-treated tumors and the \# denotes significance $(P<0.05)$ from 5 -FU-treated tumors.

Table 2 The effect of chronic resveratrol treatment $+/-5$-FU in vivo on serum levels of liver enzymes

\begin{tabular}{lcccc}
\hline & Vehicle & Resveratrol & 5-FU & $\begin{array}{c}\text { Resveratrol } \\
+5-\mathrm{FU}\end{array}$ \\
\hline $\begin{array}{l}\text { Serum AST } \\
\text { (NR 59-247 U/L) }\end{array}$ & $61.25 \pm 5.62$ & $77.5 \pm 17.34$ & $67.67 \pm 10.47$ & $87.5 \pm 18.37$ \\
$\begin{array}{l}\text { Serum ALT } \\
\text { (NR 28-132 U/L) }\end{array}$ & $39.5 \pm 2.60$ & $41.25 \pm 7.85$ & $30 \pm 5.03$ & $45.5 \pm 16.73$ \\
\hline
\end{tabular}

Data is average \pm s.e.m. $n=4$.

NR, normal range. 


\section{Resveratrol Treatment Renders Cholangiocarcinoma Tumors More Susceptible to 5-FU In Vivo}

Treatment of an in vivo xenograft model of cholangiocarcinoma with 5 -FU $(10 \mathrm{mg} / \mathrm{kg} /$ day $)$ significantly reduced tumor growth (Figure 3a) and increased tumor latency (Figure 3b) compared with vehicle-treated mice as expected. Chronic treatment of mice with $10 \mathrm{mg} / \mathrm{kg}$ resveratrol also decreased tumor growth (Figure 3a) and increased tumor latency (Figure 3b) compared with vehicle, although not to the same degree as 5-FU. However, combination therapy of resveratrol $(10 \mathrm{mg} / \mathrm{kg})$ and $5-\mathrm{FU}(10 \mathrm{mg} / \mathrm{kg} /$ day $)$ decreased tumor growth (Figure 3a) and increased tumor latency (Figure 3b) to a greater degree than 5-FU alone, providing further evidence to suggest that using resveratrol as an adjunct therapy may decrease the chemoresistance of these tumors.
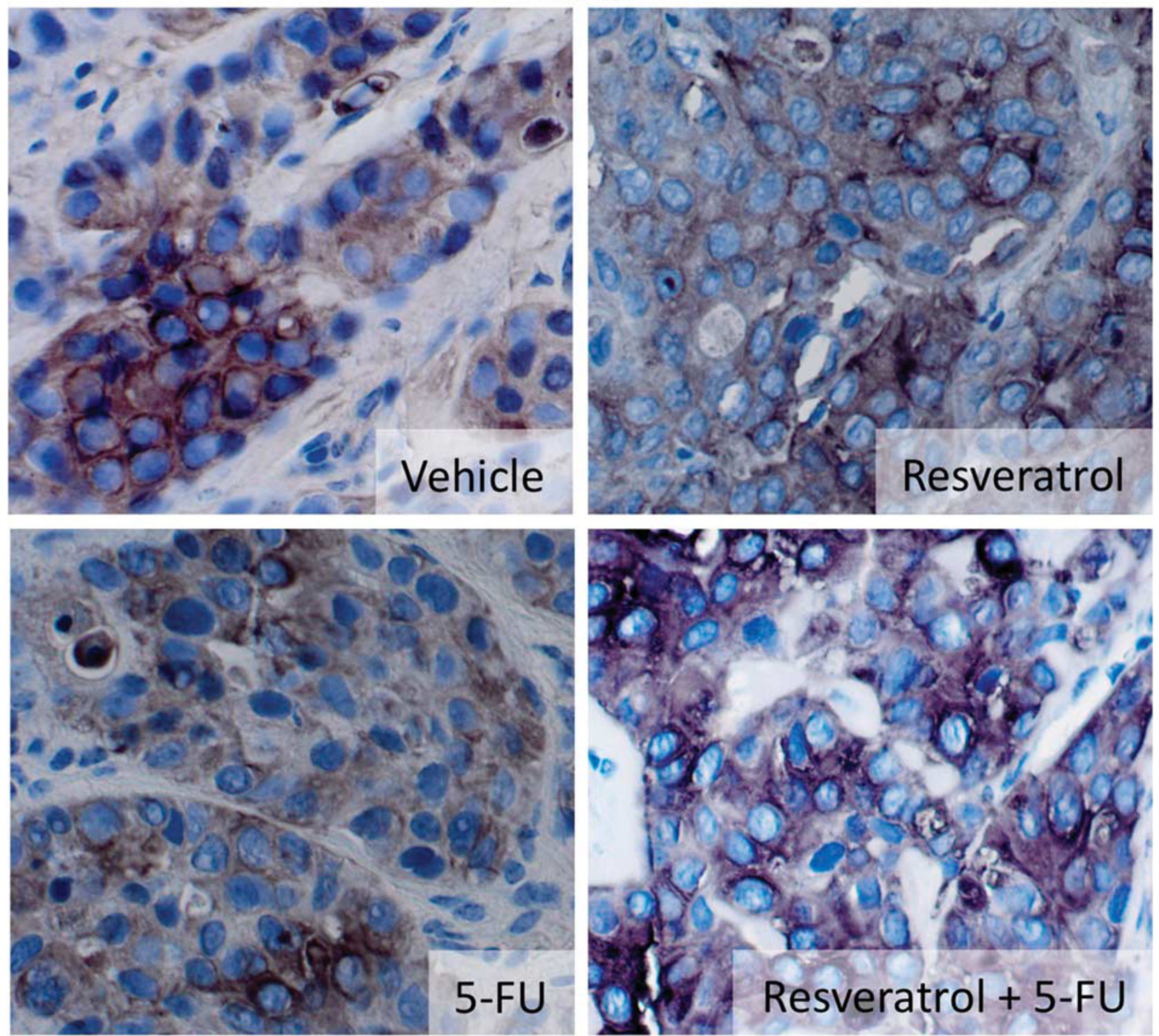

Figure 4 Immunohistological analysis of tumors. Immunohistochemistry on tumors from vehicle-, resveratrol, 5-FU, and resveratrol +5 -FU-treated mice were performed using specific antibodies against CK-19 (a), PCNA (b), and TUNEL (c). Representative photomicrographs of the immunoreactivity are shown (magnification $\times 40$ ) and positive staining is indicated by arrows. Semi-quantitative analysis of PCNA immunoreactivity was performed and data was expressed as average ( \pm s.e.m.) PCNA-positive nuclei per field $(\mathbf{b})$ and the asterisk denotes significance $(P<0.05)$ compared with vehicle-treated tumors and the \# denotes significance $(P<0.05)$ from 5-FU-treated tumors. PCNA expression in the tumors was also assessed by real-time PCR $(\mathbf{b})$. Data are expressed as average \pm s.e.m. $(n=3)$. Asterisk denotes significance $(P<0.05)$ compared with vehicle-treated tumors. Semi-quantitative analysis of TUNEL-positive nuclei was assessed and expressed as average $( \pm$ s.e.m.) PCNA-positive nuclei per field $(\mathbf{c})$ and the asterisk denotes significance $(P<0.05)$ compared with vehicletreated tumors and the \# denotes significance $(P<0.05)$ from 5 -FU-treated tumors. 
b
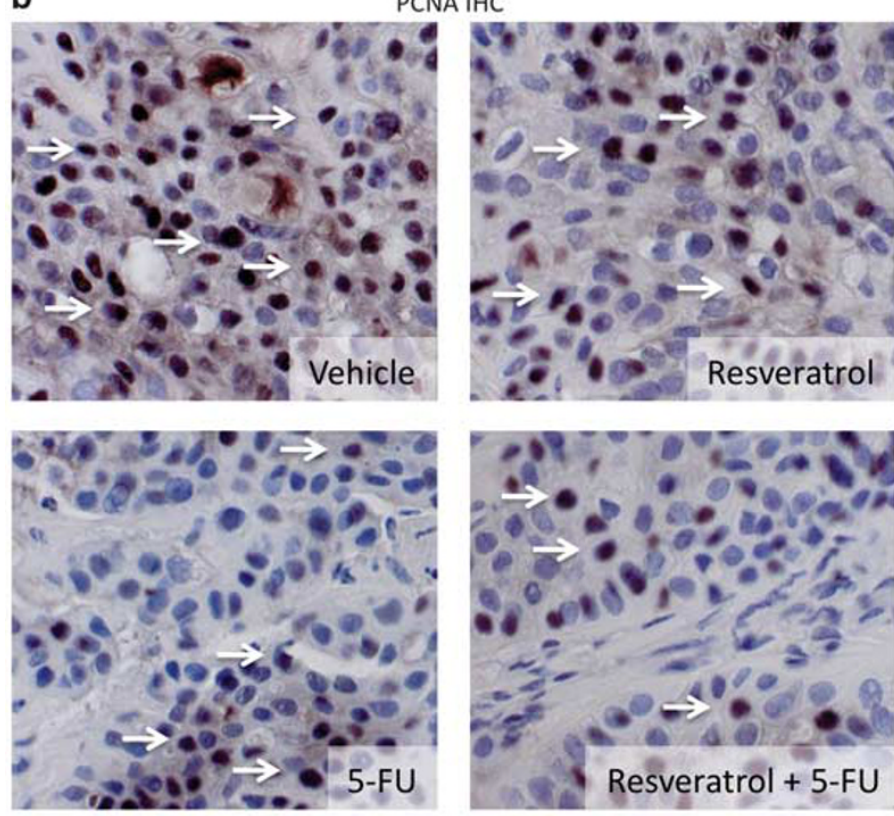

TUNEL
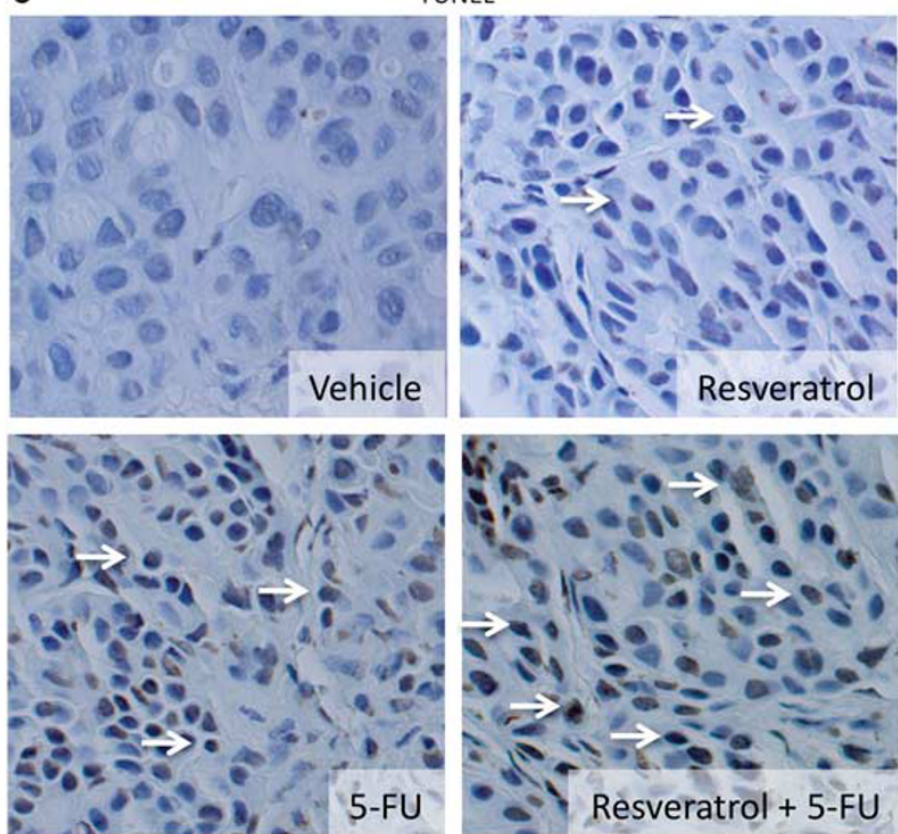
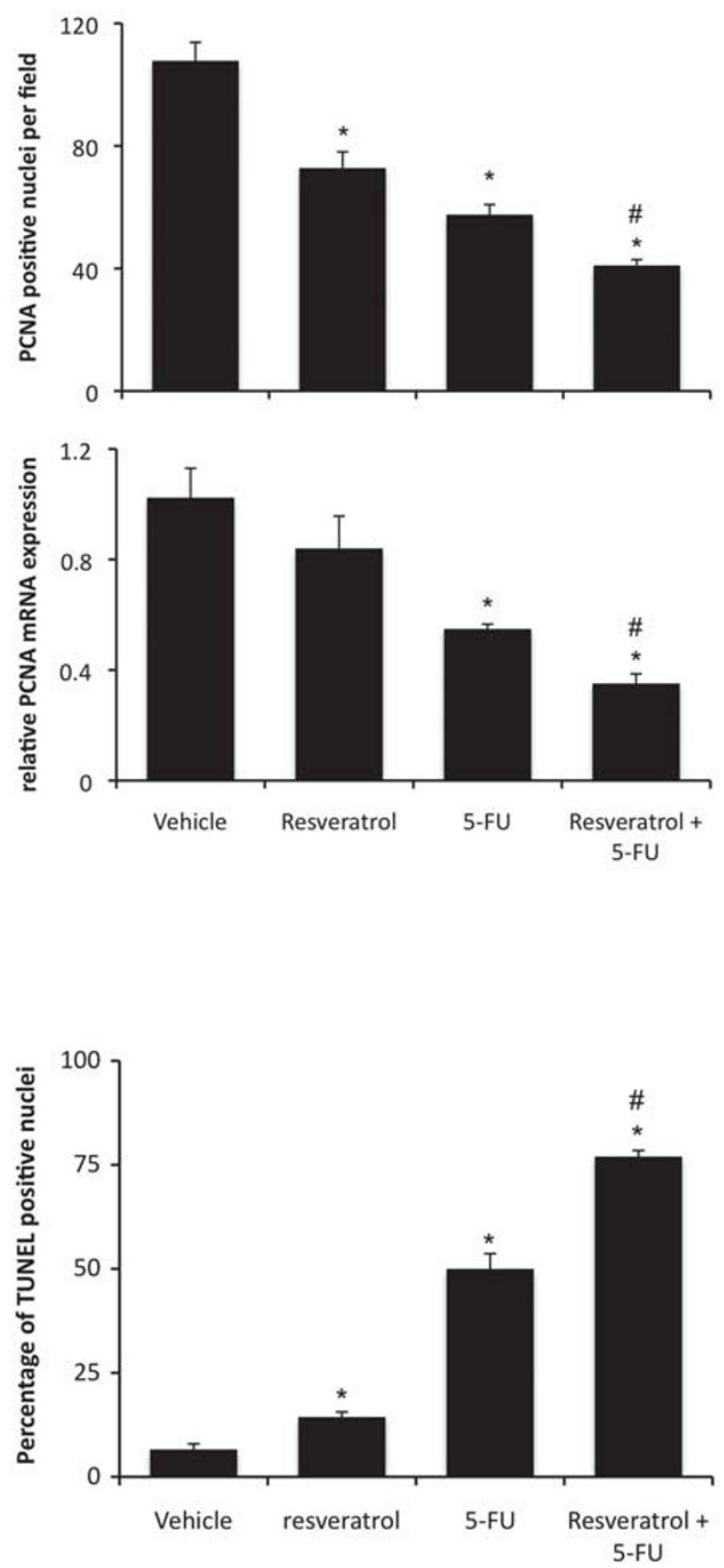

Figure 4 Continued.

Analysis of liver enzymes in the serum revealed that there was no significant difference in AST and ALT levels between any of the treatment groups (Table 2), all of which fell within normal range, suggesting that these treatments were well tolerated and did not cause any liver damage.

Histological analysis of the excised tumors revealed that most of the cells from tumors of all treatment groups were CK-19 positive, indicating a cholangiocyte phenotype (Figure 4a). Using PCNA immunoreactivity as a marker of proliferative capacity, resveratrol and 5-FU treatment decreased the number of PCNA-positive nuclei per field compared with vehicle treatment, whereas the combination of resveratrol and 5-FU decreased PCNA positive to an even greater extent than either treatment alone (Figure $4 \mathrm{~b}$ ). This pattern of PCNA expression was confirmed by real-time PCR analysis of RNA extracted from the excised tumors (Figure 4b). In parallel, using TUNEL staining as a marker of apoptosis, resveratrol treatment slightly increased the 

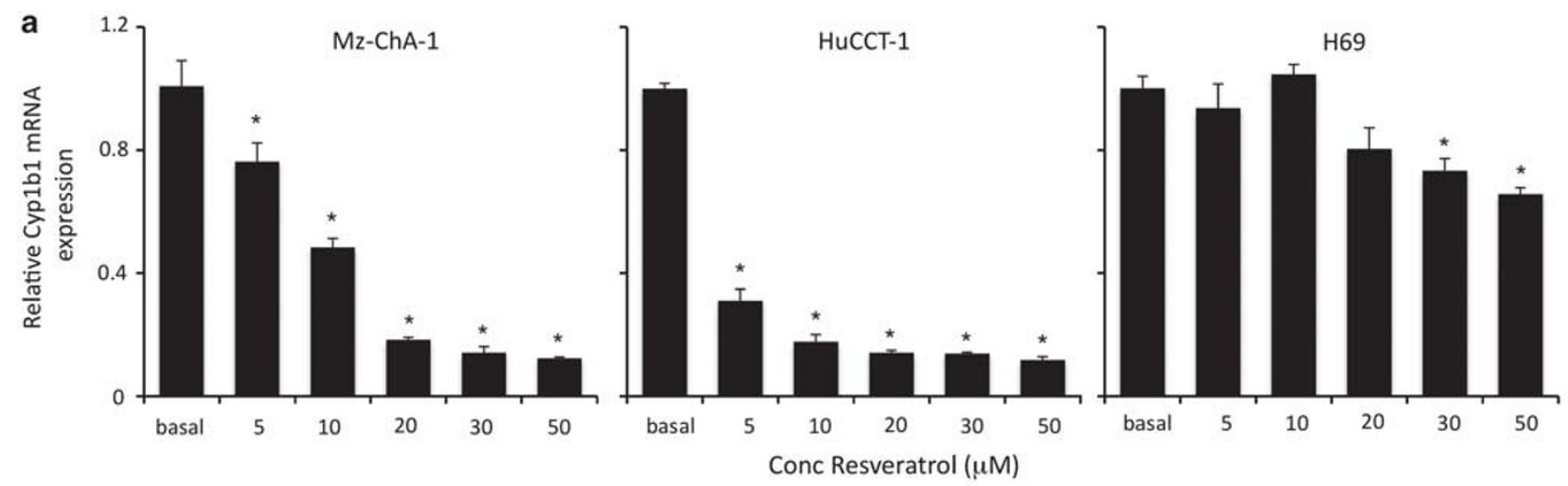

b

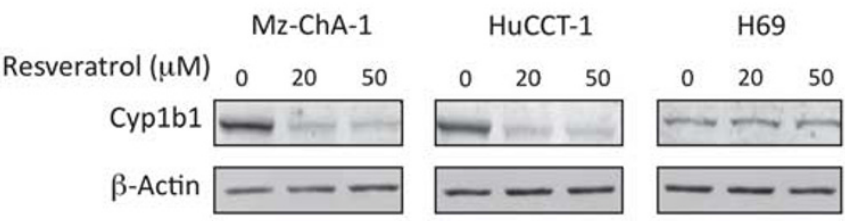

c

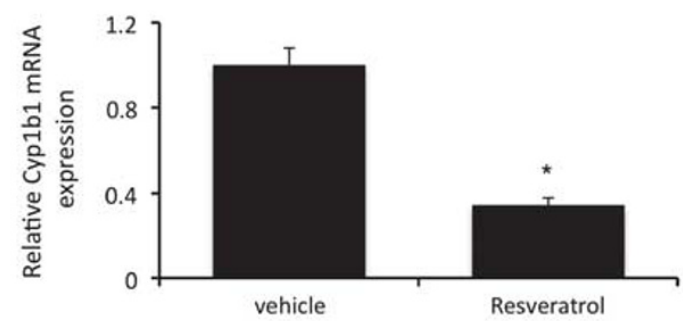

Cyp1b1 IHC
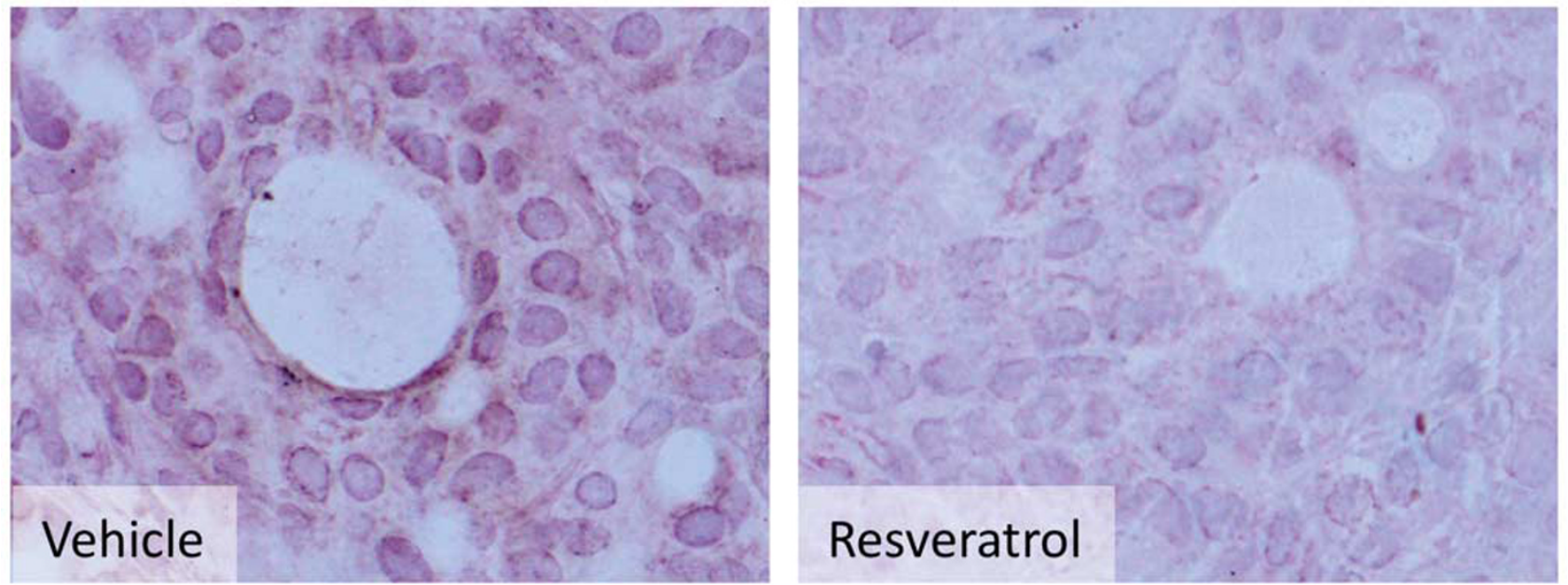

Figure 5 Resveratrol treatment of cholangiocarcinoma cells suppressed the expression of Cyp1b1 in vitro and in vivo. Cholangiocarcinoma cells (Mz-ChA-1 and HuCCT-1) and non-malignant cholangiocytes (H69) were treated with various concentrations of resveratrol (5-50 $\mu \mathrm{M})$ and Cyp1b1 mRNA expression was assessed by real-time PCR (a). Asterisk denotes significance $(P<0.05)$ compared basal levels of Cyp1b1. Cyp1b1 protein expression was assessed by immunoblotting in cell lines after in vitro resveratrol treatment. Representative blots are shown (b). (c) The effects of resveratrol treatment on Cyp1b1 expression was assessed in chronically treated cholangiocarcinoma tumors by real-time PCR (top panel) and immunohistochemistry (bottom panel).

percentage of TUNEL-positive nuclei per field compared with vehicle treatment (Figure 4c). There was also a modest increase after 5-FU increased, but the co-treatment of resveratrol and 5-FU increased the incidence of apoptosis beyond either treatment alone (Figure $4 \mathrm{c}$ ).

\section{Resveratrol Decreases the Expression of Cyp1b1}

Resveratrol has earlier been shown to decrease the expression of Cyp 1 b1 and other enzymes responsible for the metabolism of xenobiotics. ${ }^{28}$ Here, we wished to determine whether resveratrol also decreased the expression of Cyp1b1 in 

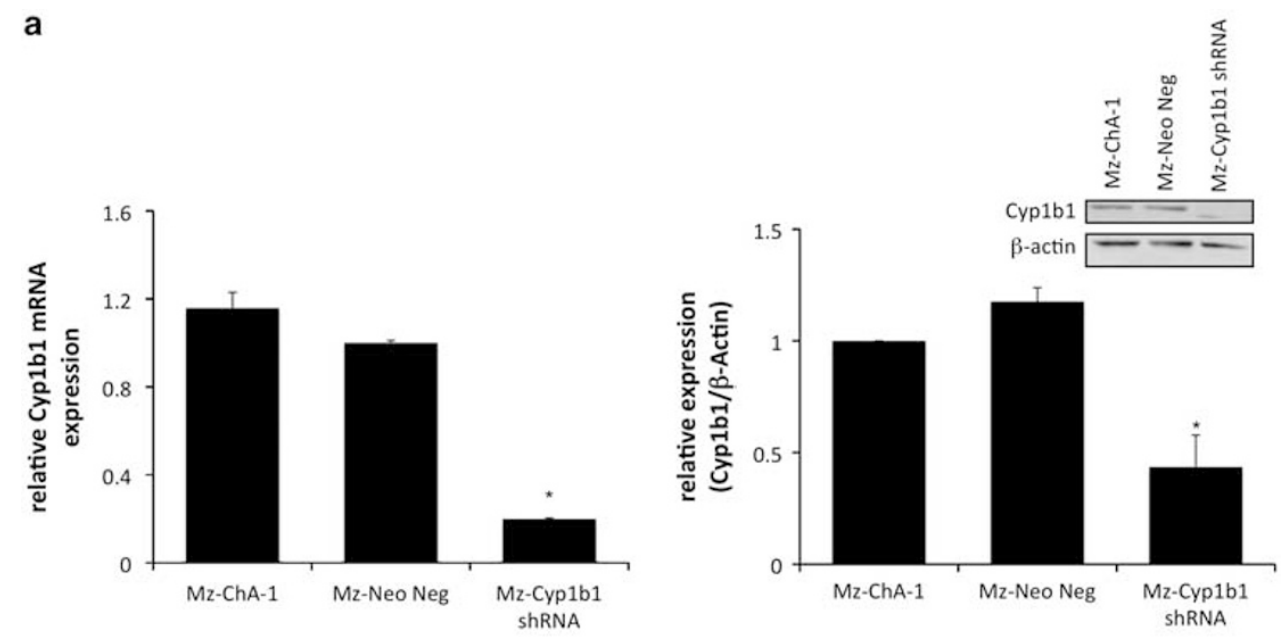

b
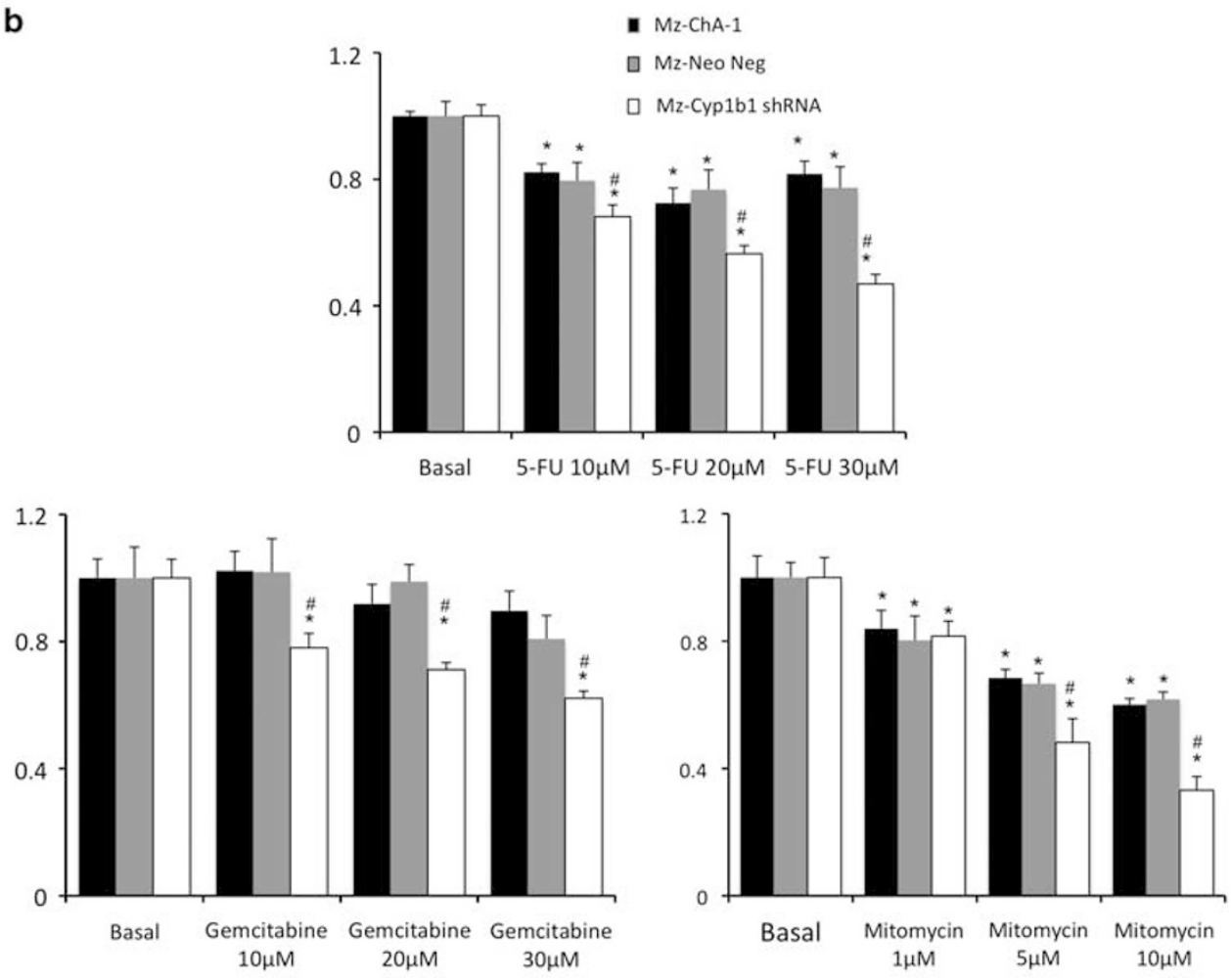

Figure 6 Specific knockdown of Cyp1b1 expression renders cholangiocarcinoma cells more susceptible to chemotherapeutic agents. Mz-ChA-1 cells were stably transfected with Cyp1b1 shRNA vectors. The expression of Cyp1b1 was assessed in the mock-transfected cell line (Mz-Neo Neg) and the cell line containing the Cyp1b1 shRNA (Mz-Cyp1b1 shRNA) real-time PCR and immunoblotting (a). Data are expressed as average \pm s.e.m. after correction for GAPDH expression or $\beta$-actin, respectively. ${ }^{*}$ denotes significance $(P<0.05)$ from Mz-ChA-1 cells. The effect of chemotherapy treatment on cell proliferation was assessed by MTS assays (b). The three cell lines (Mz-ChA-1, Mz-Neo Neg, and Mz-Cyp1b1 shRNA) were treated with 5-FU (10-30 $\mu \mathrm{M})$, gemcitabine (10-30 $\mu \mathrm{M})$, or mitomycin $\mathrm{C}(1-10 \mu \mathrm{M})$ for $48 \mathrm{~h}$ and data are expressed as fold change in proliferation (average \pm s.e.m., $n=7$ ). ${ }^{*}$ denotes $P<0.05$ compared with basal treatment within each cell line and \# denotes significance compared with the effects of these chemotherapeutic agents compared with Mz-ChA-1 cells.

cholangiocarcinoma cells. Treating two cell lines (Mz-ChA-1 and HuCCT-1) with various concentrations of resveratrol decreased cyp1b1 mRNA expression as shown by real-time PCR analysis (Figure 5a) and Cyp1b1 protein expression (Figure 5b) as shown by immunoblotting. In addition, chronic treatment of nude mice with resveratrol also decreased Cyp1b1 mRNA expression and immunoreactivity in cholangiocarcinoma tumors (Figure $5 \mathrm{c}$ ).

\section{Suppression of Cyp1b1 Expression Renders Cholangiocarcinoma Cells and Tumors More Susceptible to Chemotherapeutic Agents In Vitro and In Vivo}

We then wished to determine whether the dampened expression of Cyp1b1 in cholangiocarcinoma cells renders them more susceptible to chemotherapeutic agents. To do this, we established stable-transfected cell lines using Cyp1b1specific shRNA constructs. Once established, the relative 
Table 3 Efficacy of chemotherapeutic agents in stabletransfected cell lines

\begin{tabular}{lccc}
\hline Chemotherapy & Mz-ChA-1 & Mz-Neo Neg & Mz-Cyp1b1 shRNA \\
\hline 5-FU $(\mu \mathrm{M})$ & 95.01 & 87.67 & 25.51 \\
Mitomycin C $(\mu \mathrm{M})$ & 9.56 & 8.58 & 4.71 \\
Gemcitabine $(\mu \mathrm{M})$ & 101.1 & 95.78 & 37.93 \\
\hline
\end{tabular}

Cell lines were treated with various concentrations of 5-FU $(1-100 \mu \mathrm{M})$, mitomycin $\mathrm{C}(1-50 \mu \mathrm{M})$, or gemcitabine $(1-100 \mu \mathrm{M})$. The $\mathrm{IC}_{50}$ dose was calculated as the dose of the chemotherapeutic agent required to inhibit the proliferation to $50 \%$ of the untreated cells in an MTS cell proliferation assay.

Cyp1b1 expression was determined by real-time PCR and immunoblotting (Figure 6a). The mock-transfected cell line (Mz-Neo neg) expressed Cyp1b1 to a similar level as the parental cell line (Mz-ChA-1), in which the stably transfected Mz-Cyp1b1 shRNA cell line expressed approximately $20 \%$ or the parental and mock-transfected cell lines (Figure 6a). These cell lines were then treated with low doses of 5-FU $(10-30 \mu \mathrm{M})$, gemcitabine $(10-30 \mu \mathrm{M})$, or mitomycin $\mathrm{C}$ $(1-10 \mu \mathrm{M})$ to determine the relative sensitivity of these cell lines to these agents. Mz-Cyp1b1 shRNA cells were dramatically more susceptible to all agents studied (Figure 6b). Indeed, dampened Cyplb1 expression decreased the dose required to achieve $50 \%$ reduction in cell proliferation $\left(\mathrm{IC}_{50}\right.$; Table 3).

We then established xenograft tumors of cholangiocarcinoma using the Mz-Cyp1b1 shRNA and Mz-Neo neg and determined the relative effects of 5 -FU on these tumors. The Mz-Cyp1b1 shRNA cell line maintained the suppressed levels of Cyplb1 expression throughout the in vivo experiments (data not shown). As the Mz-Cyp1b1 cell line and the mocktransfected control cell line had slightly different tumorigenicity and growth rates (data not shown), we expressed the tumor volumes as a percentage of the corresponding vehicletreated cell line at each time point measured, and clearly showed that the tumors derived from cells with suppressed Cyp1b1 expression are more susceptible to 5-FU treatment (Figure 7).

Once again, histological analysis of the resulting tumors revealed that most of the cells have a cholangiocyte phenotype (as shown by CK-19 immunoreactivity; Figure 8a). The amount of PCNA-positive nuclei per field decreased after 5 -FU treatment in tumors derived from both the Mz-Cyp1b1 shRNA cell line and the mock-transfected Mz-Neo neg cell line (Figure 8b); however, this decrease was more evident in the Mz-ChA-1 shRNA-derived tumors. This pattern of PCNA expression was also confirmed by real-time PCR in RNA extracted from the excised tumors (Figure 8b). Conversely, 5FU treatment increased the incidence of apoptosis in tumors derived from both cell lines (Figure 8c); however, as expected, the effect was more dramatic in the tumors derived from the Mz-Cyp1b1 shRNA cell line (Figure 8c). Analysis of liver

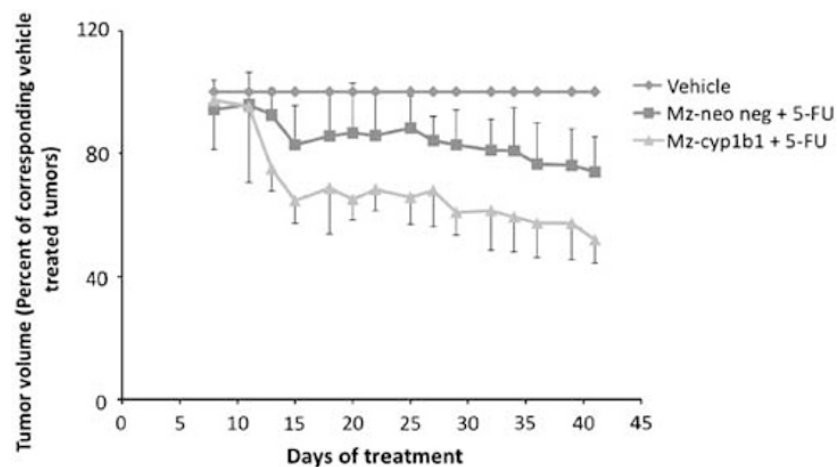

Figure 7 Genetic knockdown of Cyp1b1 expression renders the resulting cholangiocarcinoma tumors more susceptible to 5-FU treatment. Mz-Neo Neg cells or Mz-Cyp1b1 shRNA cells were injected into the flank of athymic mice. After tumors were established, mice were treated with $10 \mathrm{mg} / \mathrm{kg} / \mathrm{day}$ of 5-FU 3 days per week for 40 days and tumor volume assessed. As these two cell lines had different tumorigenicity and growth rates, for clarity of presentation, tumor volumes are expressed as a percentage of the corresponding vehicle-treated tumor at each time point measured.

enzymes in the serum revealed that there was no significant difference in AST and ALT levels between any of the treatment groups (data not shown).

\section{DISCUSSION}

The major findings presented here relate to the efficacy of resveratrol as an adjunct therapy for the treatment of cholangiocarcinoma, a relatively chemoresistant cancer. Specifically, treatment of cholangiocarcinoma cells and tumors with low concentrations of resveratrol increased the sensitivity to various chemotherapeutic agents currently used for the treatment of cholangiocarcinoma. In parallel, resveratrol treatment decreased the expression of Cyp1b1, and genetic knockdown of Cyp1b1 rendered the cells and tumors more susceptible to the same chemotherapeutic agents as above, suggesting that the level of Cyp1b1 expression may correlate to the relative chemoresistance of these cells. Taken together, these data suggest that resveratrol may be useful as an adjunct therapy for the treatment of cholangiocarcinoma.

Resveratrol has long been suggested as an effective, naturally occurring chemopreventive agent. ${ }^{20}$ It has been shown to regulate and suppress events associated with tumor initiation and promotion. Specifically, resveratrol can act as an antioxidant and an antimutagen, thereby suppressing the important features of tumor initiation. ${ }^{20}$ Resveratrol also mediates anti-inflammatory events associated with tumor promotion by inhibiting prostaglandin release, ${ }^{45-47}$ as well as cyclooxygenase and hydroperoxidase functions. ${ }^{20,48}$ Indeed, dietary administration of resveratrol caused a decrease in 7,12-dimethylbenz[a] anthracene-induced rat mammary carcinogenesis and extended the latency period of tumor development. $^{22}$ Within the liver, resveratrol has been shown to exert antiproliferative and antimigratory effects on cholangiocarcinoma cells in vitro ${ }^{5}$ and has been identified using a 
bioinformatic screening approach, as an important therapeutic agent for the treatment of hepatocellular carcinoma because of its ability to reverse migratory and invasive phenotypes. ${ }^{7}$ The data presented in this study also suggests a function for resveratrol in reducing the resistance of cholangiocarcinoma to chemotherapeutic agents in vitro and in vivo.

In support of our data, the resveratrol-induced decrease in resistance to chemotherapeutics has earlier been shown in human oral epidermoid carcinoma cells. ${ }^{49}$ Specifically, resveratrol rendered these cells more susceptible to the chemotherapeutics, vincristine, adriamycin, and paclitaxel through a mechanism that was associated with decreased expression of the multidrug-resistant gene MDR1. ${ }^{49}$ Furthermore, resveratrol treatment increases the sensitivity of cancer stem-like cells to radiotherapy, although the precise mechanism for this is unknown. ${ }^{50}$ Another mechanism by which resveratrol may increase sensitivity to chemotherapyinduced apoptosis lies in its ability to redistribute the death receptors (DR), Fas, DR4, and DR5 into lipid raft structures thereby facilitating the formation of the death receptor complex and rendering these cells more sensitive to death

CK19 IHC
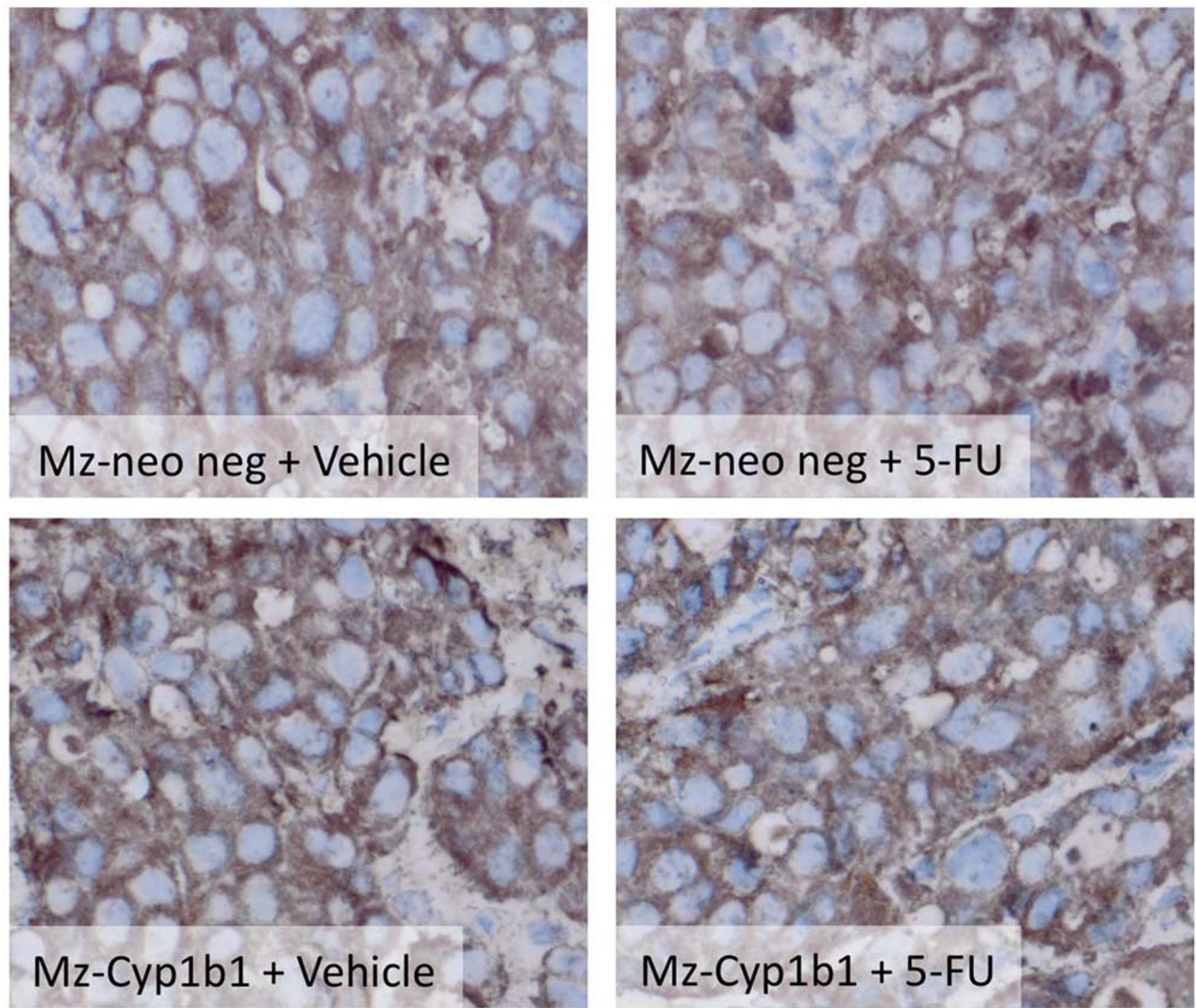

Figure 8 Immunohistological analysis of tumors. Immunohistochemistry on tumors derived from Mz-Neo neg cells and Mz-Cyp1b1 shRNA cells treated with vehicle of 5-FU were performed using specific antibodies against CK-19 (a), PCNA (b), and TUNEL (c). Representative photomicrographs of the immunoreactivity are shown (magnification $\times 40$ ) and positive immunoreactivity indicated by arrows. Semi-quantitative analysis of PCNA immunoreactivity was performed and data was expressed as average ( \pm s.e.m.) PCNA-positive nuclei per field and also by real-time PCR (b). Data are expressed as average \pm s.e.m. $(n=3)$. Semi-quantitative analysis of TUNEL-positive nuclei was assessed and expressed as average ( \pm s.e.m.) PCNA-positive nuclei per field (c). In each case, the asterisk denotes significance $(P<0.05)$ compared with the corresponding vehicle-treated tumors and the \# denotes significance $(P<0.05)$ from 5-FU-treated tumors derived from the Mz-neo neg cells. 
b
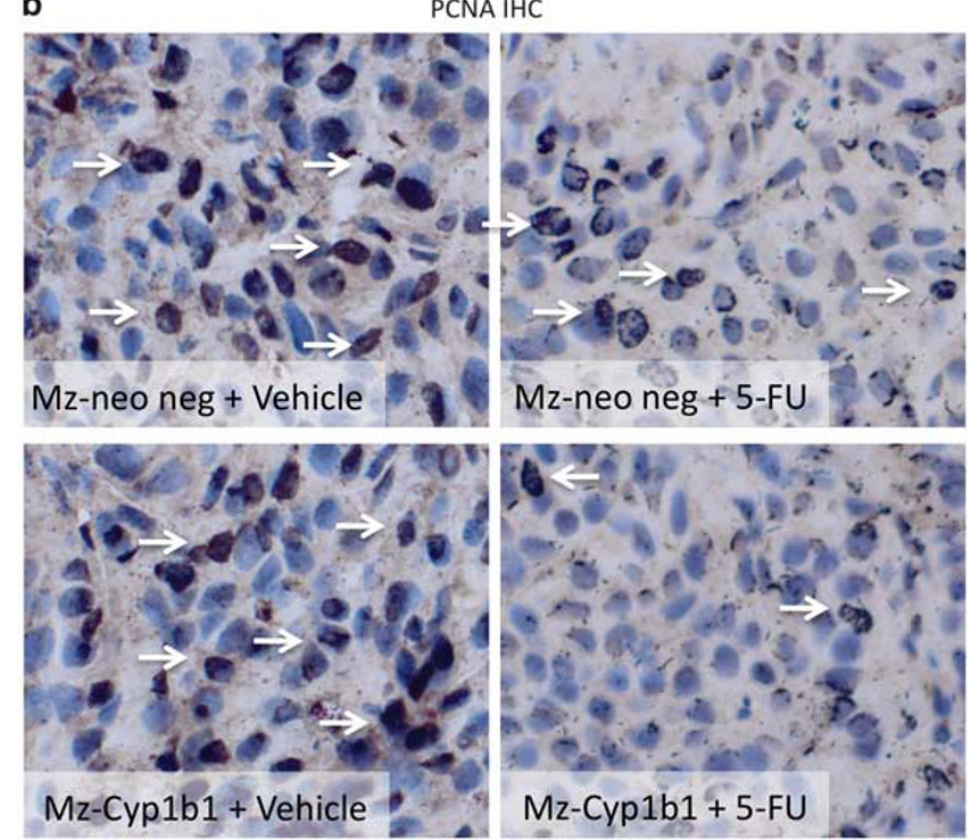

C
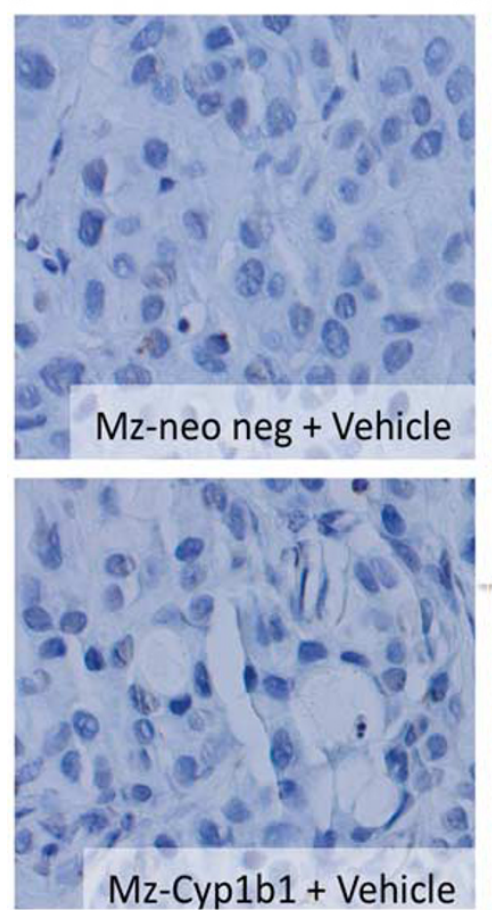

TUNEL
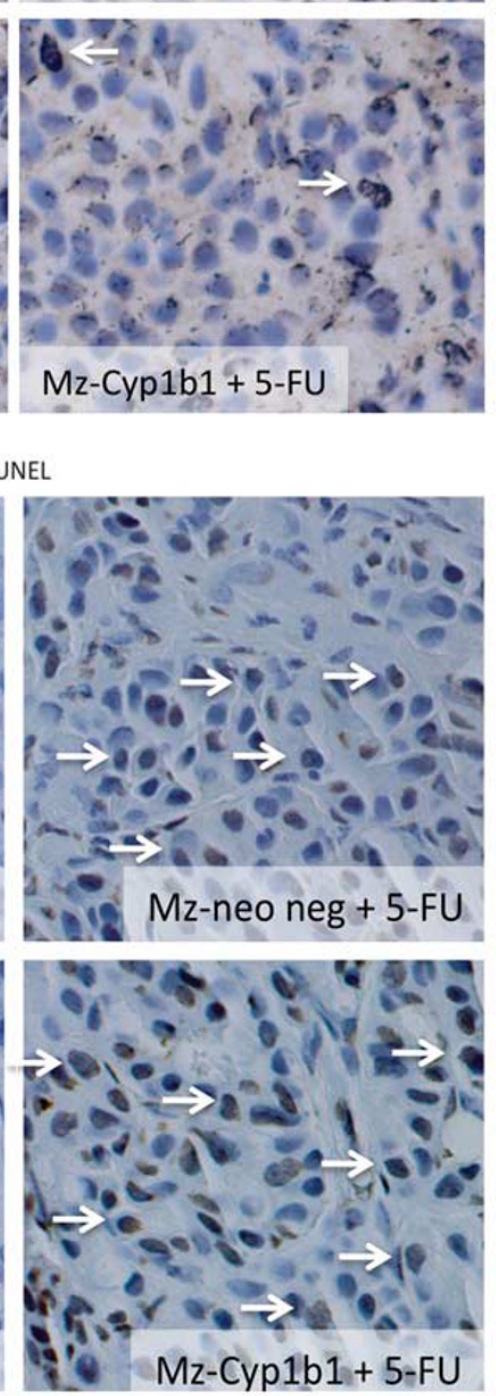

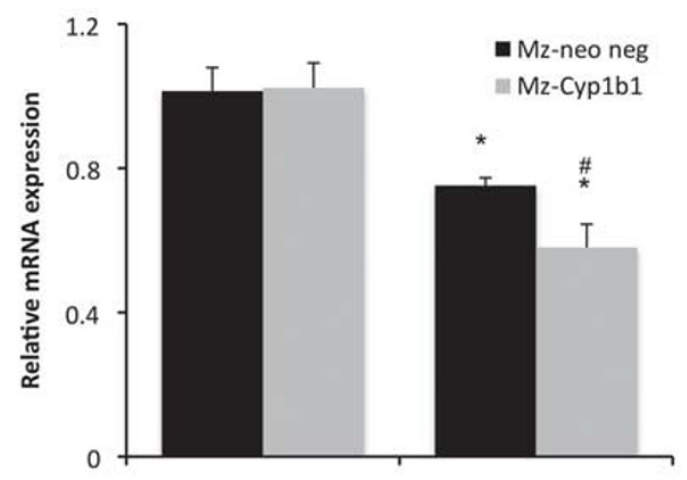

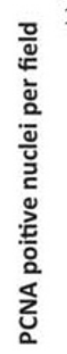

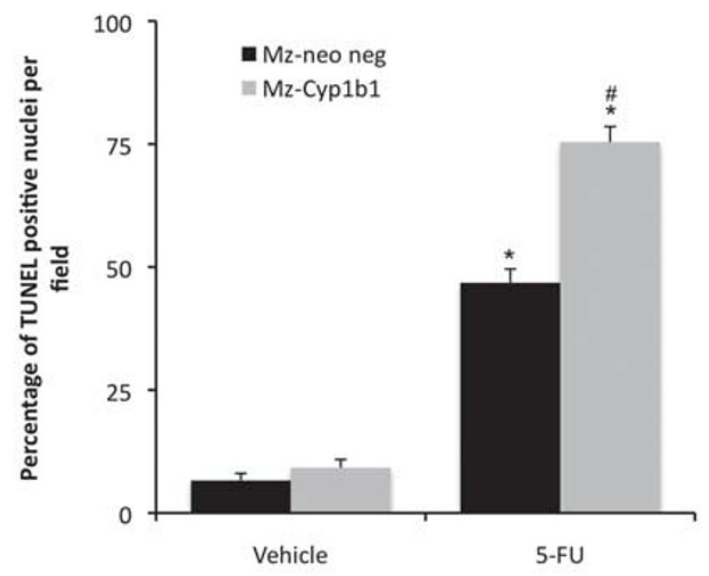

Figure 8 Continued.

receptor ligand-induced cell death. ${ }^{17,18}$ It is this death receptor pathway that is impaired in a number of chemoresistant tumors such as cholangiocarcinoma ${ }^{51}$ and pancreatic cancer $^{52}$ and treatments that may reverse this impairment may increase the sensitivity of these tumors to chemotherapeutic strategies. In contrast, our data suggests that resveratrol sensitizes cholangiocarcinoma cells to a number of chemotherapeutic agents through the decreased expression of
Cyp1b1. However, the possibility that resveratrol is also facilitating death receptor complex formation in these cells cannot be ruled out.

Cyp1b1 has earlier been shown to have a function in the bioactivation of several procarcinogens to carcinogenic derivatives ${ }^{53}$ and also to detoxify several xenobiotic compounds ${ }^{28}$ including various chemotherapeutic agents. ${ }^{33}$ It has also been shown to be overexpressed in a number of 
tumors. ${ }^{29-31,54,55}$ Owing to this, agents that suppress the expression of Cyp1b1 have been touted as useful chemopreventive agents. Evidence to suggest that resveratrol may also exert its chemopreventive actions through the inhibition of Cyp1b1 expression has earlier been shown. ${ }^{23-25}$ The molecular mechanism by which resveratrol regulates the expression of Cyp1b1 is largely unknown and is the topic of ongoing research in our laboratory.

In conclusion, the data presented here clearly showed a function for low doses of resveratrol in the sensitivity of cholangiocarcinoma to chemotherapy-induced cell death. In addition, we show that suppression of Cyp1b1 expression may be one mechanism by which resveratrol renders these cells more susceptible to chemotherapy. Taken together with the current literature, we propose that the use of adjunct therapies aimed at overcoming the detoxification of chemotherapeutics and/or increasing the sensitivity to intrinsic death pathways may be explored for the treatment of chemoresistant tumors such as cholangiocarcinoma.

\section{ACKNOWLEDGEMENTS}

We sincerely thank Dr Gianfranco Alpini for his assistance and expert advice in the development of this manuscript. In addition, we thank Ms Monique Coufal and Mr Andrew Brennan for their technical assistance. This work was supported by an NIH K01 grant award (DK078532) to Dr DeMorrow, and a state scholarship of China Scholarship Council to Dr Huang.

\section{DISCLOSURE/CONFLICT OF INTEREST}

The authors declare no conflict of interest.

1. Blechacz B, Gores GJ. Tumor-specific marker genes for intrahepatic cholangiocarcinoma: utility and mechanistic insight. J Hepatol 2008:49:160-162.

2. Blechacz BR, Gores GJ. Cholangiocarcinoma. Clin Liver Dis 2008;12:131-150, ix.

3. Gores GJ. Cholangiocarcinoma: current concepts and insights. Hepatology 2003;37:961-969.

4. Sirica AE. Cholangiocarcinoma: molecular targeting strategies for chemoprevention and therapy. Hepatology 2005;41:5-15.

5. Roncoroni L, Elli L, Dolfini $E$, et al. Resveratrol inhibits cell growth in a human cholangiocarcinoma cell line. Liver Int 2008;28:1426-1436.

6. Mouria M, Gukovskaya AS, Jung Y, et al. Food-derived polyphenols inhibit pancreatic cancer growth through mitochondrial cytochrome $C$ release and apoptosis. Int J Cancer 2002;98:761-769.

7. Braconi C, Meng F, Swenson E, et al. Candidate therapeutic agents for hepatocellular cancer can be identified from phenotype-associated gene expression signatures. Cancer 2009;115:3738-3748.

8. Onori $\mathrm{P}$, DeMorrow $\mathrm{S}$, Gaudio $\mathrm{E}$, et al. Caffeic acid phenethyl ester decreases cholangiocarcinoma growth by inhibition of NF-kappaB and induction of apoptosis. Int J Cancer 2009;125:565-576.

9. Naus PJ, Henson R, Bleeker G, et al. Tannic acid synergizes the cytotoxicity of chemotherapeutic drugs in human cholangiocarcinoma by modulating drug efflux pathways. J Hepatol 2007;46:222-229.

10. Lang $M$, Henson $R$, Braconi $C$, et al. Epigallocatechin-gallate modulates chemotherapy-induced apoptosis in human cholangiocarcinoma cells. Liver Int 2009;29:670-677.

11. Soory M. Relevance of nutritional antioxidants in metabolic syndrome, ageing and cancer: potential for therapeutic targeting. Infect Disord Drug Targets 2009;9:400-414.

12. Chen MJ, Chang WH, Lin CC, et al. Caffeic acid phenethyl ester induces apoptosis of human pancreatic cancer cells involving caspase and mitochondrial dysfunction. Pancreatology 2008;8:566-576.
13. Demestre M, Messerli SM, Celli N, et al. CAPE (caffeic acid phenethyl ester)-based propolis extract (Bio 30) suppresses the growth of human neurofibromatosis (NF) tumor xenografts in mice. Phytother Res 2009;23:226-230.

14. Wu CS, Chen MF, Lee IL, et al. Predictive role of nuclear factor-kappaB activity in gastric cancer: a promising adjuvant approach with caffeic acid phenethyl ester. J Clin Gastroenterol 2007;41:894-900.

15. Tang HY, Shih A, Cao HJ, et al. Resveratrol-induced cyclooxygenase-2 facilitates p53-dependent apoptosis in human breast cancer cells. Mol Cancer Ther 2006;5:2034-2042.

16. Su JL, Yang CY, Zhao M, et al. Forkhead proteins are critical for bone morphogenetic protein-2 regulation and anti-tumor activity of resveratrol. J Biol Chem 2007;282:19385-19398.

17. Delmas D, Rebe C, Lacour S, et al. Resveratrol-induced apoptosis is associated with Fas redistribution in the rafts and the formation of a death-inducing signaling complex in colon cancer cells. J Biol Chem 2003;278:41482-41490.

18. Delmas D, Rebe C, Micheau O, et al. Redistribution of CD95, DR4 and DR5 in rafts accounts for the synergistic toxicity of resveratrol and death receptor ligands in colon carcinoma cells. Oncogene 2004;23:8979-8986.

19. Benitez DA, Pozo-Guisado E, Alvarez-Barrientos A, et al. Mechanisms involved in resveratrol-induced apoptosis and cell cycle arrest in prostate cancer-derived cell lines. J Androl 2007;28:282-293.

20. Jang M, Cai L, Udeani GO, et al. Cancer chemopreventive activity of resveratrol, a natural product derived from grapes. Science 1997;275:218-220.

21. Li ZG, Hong T, Shimada $Y$, et al. Suppression of N-nitrosomethylbenzylamine (NMBA)-induced esophageal tumorigenesis in $\mathrm{F} 344$ rats by resveratrol. Carcinogenesis 2002;23:1531-1536.

22. Banerjee S, Bueso-Ramos C, Aggarwal BB. Suppression of 7,12 dimethylbenz(a)anthracene-induced mammary carcinogenesis in rats by resveratrol: role of nuclear factor-kappaB, cyclooxygenase 2 , and matrix metalloprotease 9. Cancer Res 2002;62:4945-4954.

23. Liu J, Wang $\mathrm{Q}, \mathrm{Wu} \mathrm{DC}$, et al. Differential regulation of CYP1A1 and CYP1B1 expression in resveratrol-treated human medulloblastoma cells. Neurosci Lett 2004;363:257-261.

24. Chen $\mathrm{ZH}$, Hurh $\mathrm{YJ}, \mathrm{Na} \mathrm{HK}$, et al. Resveratrol inhibits TCDD-induced expression of CYP1A1 and CYP1B1 and catechol estrogen-mediated oxidative DNA damage in cultured human mammary epithelial cells. Carcinogenesis 2004;25:2005-2013.

25. Mikstacka R, Przybylska D, Rimando AM, et al. Inhibition of human recombinant cytochromes P450 CYP1A1 and CYP1B1 by transresveratrol methyl ethers. Mol Nutr Food Res 2007;51:517-524.

26. Jefcoate CR, Liehr JG, Santen RJ, et al. Tissue-specific synthesis and oxidative metabolism of estrogens. J Natl Cancer Inst Monogr 2000; 95-112.

27. Shimada T, Watanabe J, Kawajiri K, et al. Catalytic properties of polymorphic human cytochrome P450 1B1 variants. Carcinogenesis 1999;20:1607-1613.

28. Shimada T, Gillam EM, Sutter TR, et al. Oxidation of xenobiotics by recombinant human cytochrome P450 1B1. Drug Metab Dispos 1997;25:617-622.

29. McFadyen MC, Cruickshank ME, Miller ID, et al. Cytochrome P450 CYP1B1 over-expression in primary and metastatic ovarian cancer. $\mathrm{Br}$ J Cancer 2001;85:242-246.

30. Saini $\mathrm{S}$, Hirata $\mathrm{H}$, Majid $\mathrm{S}$, et al. Functional significance of cytochrome P450 1B1 in endometrial carcinogenesis. Cancer Res 2009;69:7038-7045.

31. Su JM, Lin P, Wang CK, et al. Overexpression of cytochrome P450 1B1 in advanced non-small cell lung cancer: a potential therapeutic target. Anticancer Res 2009:29:509-515.

32. Rochat B, Morsman JM, Murray Gl, et al. Human CYP1B1 and anticancer agent metabolism: mechanism for tumor-specific drug inactivation? J Pharmacol Exp Ther 2001;296:537-541.

33. McFadyen MC, McLeod HL, Jackson FC, et al. Cytochrome P450 CYP1B1 protein expression: a novel mechanism of anticancer drug resistance. Biochem Pharmacol 2001;62:207-212.

34. Bournique $B$, Lemarie $A$. Docetaxel (Taxotere) is not metabolized by recombinant human CYP1B1 in vitro, but acts as an effector of this isozyme. Drug Metab Dispos 2002;30:1149-1152.

35. Knuth A, Gabbert H, Dippold W, et al. Biliary adenocarcinoma. Characterisation of three new human tumor cell lines. J Hepatol 1985;1:579-596. 
36. Shimizu Y, Demetris AJ, Gollin SM, et al. Two new human cholangiocarcinoma cell lines and their cytogenetics and responses to growth factors, hormones, cytokines or immunologic effector cells. Int J Cancer 1992;52:252-260.

37. Miyagiwa M, Ichida T, Tokiwa T, et al. A new human cholangiocellular carcinoma cell line (HuCC-T1) producing carbohydrate antigen 19/9 in serum-free medium. In Vitro Cell Dev Biol 1989;25:503-510.

38. Storto PD, Saidman S L, Demetris AJ, et al. Chromosomal breakpoints in cholangiocarcinoma cell lines. Genes Chromosomes Cancer 1990;2:300-310.

39. Grubman SA, Perrone R D, Lee DW, et al. Regulation of intracellular pH by immortalized human intrahepatic biliary epithelial cell lines. Am J Physiol 1994;266(6 Part 1):G1060-G1070.

40. DeMorrow S, Glaser S, Francis $\mathrm{H}$, et al. Opposing actions of endocannabinoids on cholangiocarcinoma growth: recruitment of fas and fas ligand to lipid rafts. J Biol Chem 2007;282:13098-13113.

41. Livak KJ, Schmittgen TD. Analysis of relative gene expression data using real-time quantitative PCR and the 2(-Delta Delta C(T)) Method Methods 2001;25:402-408.

42. DeMorrow S, Francis H, Gaudio E, et al. The endocannabinoid anandamide inhibits cholangiocarcinoma growth via activation of the non-canonical Wnt signaling pathway. Am J Physiol Gastrointest Liver Physiol 2008;295:G1150-G1158.

43. Fava G, Marucci L, Glaser S, et al. gamma-Aminobutyric acid inhibits cholangiocarcinoma growth by cyclic AMP-dependent regulation of the protein kinase $A$ /extracellular signal-regulated kinase $1 / 2$ pathway. Cancer Res 2005;65:11437-11446.

44. Coufal M, Invernizzi P, Gaudio $E$, et al. Increased local dopamine secretion has growth-promoting effects in cholangiocarcinoma. Int J Cancer 2009;126:2112-2122.

45. Kim YA, Kim GY, Park KY, et al. Resveratrol inhibits nitric oxide and prostaglandin E2 production by lipopolysaccharide-activated C6 microglia. J Med Food 2007;10:218-224.
46. Kim YA, Lim SY, Rhee $\mathrm{SH}$, et al. Resveratrol inhibits inducible nitric oxide synthase and cyclooxygenase-2 expression in beta-amyloidtreated C6 glioma cells. Int J Mol Med 2006;17:1069-1075.

47. Awad AB, Burr AT, Fink CS. Effect of resveratrol and beta-sitosterol in combination on reactive oxygen species and prostaglandin release by PC-3 cells. Prostaglandins Leukot Essent Fatty Acids 2005;72:219-226.

48. Takada Y, Bhardwaj A, Potdar P, et al. Nonsteroidal anti-inflammatory agents differ in their ability to suppress NF-kappaB activation, inhibition of expression of cyclooxygenase-2 and cyclin D1, and abrogation of tumor cell proliferation. Oncogene 2004;23: 9247-9258.

49. Quan F, Pan C, Ma Q, et al. Reversal effect of resveratrol on multidrug resistance in KBv200 cell line. Biomed Pharmacother 2008;62: 622-629.

50. Kao CL, Huang PI, Tsai PH, et al. Resveratrol-induced apoptosis and increased radiosensitivity in CD133-positive cells derived from atypical teratoid/rhabdoid tumor. Int J Radiat Oncol Biol Phys 2009;74:219-228

51. Taniai M, Grambihler A, Higuchi $\mathrm{H}$, et al. $\mathrm{Mcl}-1$ mediates tumor necrosis factor-related apoptosis-inducing ligand resistance in human cholangiocarcinoma cells. Cancer Res 2004;64:3517-3524.

52. Schniewind $B$, Christgen $M$, Kurdow $R$, et al. Resistance of pancreatic cancer to gemcitabine treatment is dependent on mitochondriamediated apoptosis. Int J Cancer 2004;109:182-188.

53. Uppstad $H$, Ovrebo $S$, Haugen A, et al. Importance of CYP1A1 and CYP1B1 in bioactivation of benzo[a]pyrene in human lung cell lines. Toxicol Lett 2010;192:221-228.

54. Murray Gl, Taylor MC, McFadyen MC, et al. Tumor-specific expression of cytochrome P450 CYP1B1. Cancer Res 1997;57:3026-3031.

55. Murray Gl, Melvin WT, Greenlee WF, et al. Regulation, function, and tissue-specific expression of cytochrome P450 CYP1B1. Annu Rev Pharmacol Toxicol 2001;41:297-316. 